\title{
Development Research on Interactive Design in the Field of Environment Art Design
}

\author{
Zhao Liu, Yan Liang \\ School of Art \& Design, Lanzhou Jiaotong University, 730070, China
}

Keywords: Interactive design, Environment art design, Interaction

\begin{abstract}
The design idea of user experience emphasized by interactive design makes it have obvious advantages in environmental art design. The interactive design in the field of environment art design can be divided into four categories, which are state interaction, behavior interaction, emotion interaction and sense interaction. This paper describes the concepts and features of these categories in detail and explores the development trends of interactive design in the field of environment art design to provide some references for the relative researchers.
\end{abstract}

\section{Introduction}

"Interaction" refers to the process of communication between people and all things in nature and the interaction and influence. Design is a process of creation, a creative act of creative human creation, and is creating a more reasonable way of living. In addition to natural creation, the main link of its creation process is the design. It emphasizes the use of the user as the center, the design of a reasonable way of use. Interactive design is the design concept and method that embodies this way, which is to create a new user experience. Environmental art design involves many fields, such as architecture, landscape, indoor and public art creation, which affect people's quality of life. The city is the people and living place, as a civilized social environment, but also human mature and the civilization of environmental art design is facing unprecedented challenges and complex in the new period, in such a highly variable but inclusive Vientiane times, according to the development of environmental design history can be seen, the significance and content of design in different times have put forward different requirements. But in any case, the purpose and the object of design is always put people's needs as the primary starting point, the relationship between people as the main body to coordinate with the environment, pay attention to security, territoriality, sense of belonging and identity and other psychological feelings become a factor that cannot be ignored, but in the information society, all the leading media the times, people's sense of participation should be paid great attention. In the new era of landscape design, the interaction between human and landscape as the breakthrough point of design, and the creation of new experience and new sense of landscape works by means of modern electronic technology and digital media is one of the ways to adapt to the characteristics of the times and solve practical problems.

\section{Applications Categories of Interactive Design in the Field of Environment Art Design}

\subsection{State Interaction}

State interaction is often seen in some product designs that interact with the audience by the nature that the state does not have before the state is produced. This kind of interactive fun, can be in a very short time to get people's attention, different states will bring people different experiences. The state of interaction can be reflected in shape, color, texture, light and so on, can not only bring fresh visual and psychological impact to the audience, but also enhance the interactive works of environmental art design works of participation, but also enrich all aspects of environmental art design works. In form, for example, the folding seat can extract the morphological characteristics of some objects and apply 
them to the design of folding seats. Changing the form will have different effects, and bring different experience to users under different morphological characteristics. The virtual reality technology to break the space limitation and even time, in support of the technology, environmental design by means of a powerful and unconstrained style of the artistic concept, to further adjust the environment design scheme, which has high artistic value and practical value. There are countless professional associations between the two groups of virtual reality technology and environmental art design. We will use virtual reality technology and environment art design field, more highlights the advantages of virtual reality technology. So, we combine the two-integration effect is more prominent from the specific point of view, the environmental art design project is a type of engineering design of a large fusion display, with high-tech scene made out of the dynamic atmosphere to stimulate people's various experiences, so as to environmental design structure want more explicit and more specific understanding.

\subsection{Behavior Interaction}

By ingeniously conceiving, the designer uses some of the tourists' behavior to achieve the purpose of completing a piece of work. The designer puts the unfinished works under the public influence, and achieves the decorative effect by using the elements previously designed to act on the unfinished works through the behavior of tourists. Through the designer's conception, the original art works without dynamic changes from static state to dynamic design works. Through the interaction with the works, their participation has been enhanced, and the visitors' emotional changes have taken place. Among them, clean house is the most representative example. The original pure white interior space gradually showed unique characteristics of color and form under the continuous participation of the audience. It not only brought the audience a unique experience, but also enriched the content of the works, and realized the interaction between the design works and the audience. Space is more abstract. Therefore, it is very important to transform space into a perceptible real existence of human beings. The important attribute of space is the existence of human beings, and the surrounding space is made up of the positive form of things and the negative forms of things that are not occupied. Not only that, the life experience of human beings, which includes time factors, forms the relationship between man and space. The experience of human beings is characterized by a certain tendency as the environment is different. Because this form does not happen by chance. However, interaction provides a solution to this stage is right before the true artificial intelligence, interaction with vitality, let the limited intelligence product advantages can play to the maximum, local replace people to finish between human and machine communication is particularly important, natural interaction ideas associated with the reality, produced a new attractive interaction, expand the interactive art realm.

\subsection{Emotion Interaction}

The design work itself has a certain sense of texture. It will act on the visitors directly or indirectly through the contact with the visitors, so that visitors can feel physiological or psychological, to achieve the design intent that the designers want to convey. The design works itself can stimulate the feeling, color, smell and sound of the five senses of the tourists, which can make them produce physiological or psychological changes. Interactive design is a design that optimizes and handles the process of exchanging information between two objects. Interactive designers need to use language expressions and forms of expression. So interactive design is a user centric design. A certain space is reserved within the space of design works, and things in the reserved space will be changed with time, or the works will change at specific conditions or at a specific time. Visitors or users will get special feelings, psychological or physiological changes. Because of time and the natural conditions of external forces, the change of the form, content and form of design works will bring unexpected feelings to the audience. The design works constantly change the audience's physiological or psychological experience, which maximizes the freshness of the design works, and the audiences will not be bored with the design works themselves because of the passage of time. New interactive means, such as multi touch technology and virtual experience technology, are widely used in mobile phones and are familiar to everyone. The city wall provides citizens with information about urban culture, 
road traffic, tourist attractions, food and accommodation, and many other communication platforms. It satisfies the public's experience of interaction and interaction, creates an interactive platform between citizens and city information, and creates convenient facilities for citizens to get information. The familiar message of mobile phone is the most familiar case of information sharing, and information sharing is often transmitted in a point to point way and a bit to multi point. The screen installed in the public space of the square is a commercial function of the public facilities on the one hand, and on the other hand, it conveys public information. The citizens can send their blessings or other messages on a large screen by text messages, and complete the interaction between the citizens and the information. The entire interactive design works all around the user's needs. If the user never understands and feels the design, the design will not have any availability, and the work is a failure. At present, the public art is guided by the demand of the masses, and artistic creation is carried out on the focus of attention, reflecting the social reality. Therefore, interaction design and public art form the intersection of user demand oriented.

\subsection{Sense Interaction}

In the design using acoustic landscape to enhance landscape interest, attract the attention of the audience, the sound landscape through visual and auditory generated feelings to change the audience's psychological state, can also through the active participation of the audience to change the design work of the state, has the corresponding change. In the landscape of artificial sound, such as the Korean sound Museum, the American sound map exploration, and so on. Natural sound and water can be used to create natural sound. For example, Chinese classical gardens Garden Music stream through clever ideas sound of spring to become a major feature in the garden. The construction of sound landscape not only increases the interest of the works of environmental art design, but also improves the participation of the audience. The sense of smell is one of the five senses of human beings. By feeling the sense of smell, people produce corresponding physiological and psychological reactions. In environmental art design works, using olfactory interaction can enhance sense of experience and enhance the sense of environmental substitution, but in environmental art design, it has not been widely concerned and applied. With the gradual deepening of the research on sensory interaction design in all walks of life, the appearance of smell in the works of environmental art design will also have a certain development prospect. Because digital art can not only act on the sense organs of human beings, but also realize the perceptual expression of human feelings, psychology, thinking and experience, so it is some effective medium connecting human beings with digital art and space, and has become a new means of spatial design. The stage design of CCTV Spring Festival Gala fully reflects the charm of environmental digital art. Digital technology extends the stage image to every corner of the studio. The audience is on the ground and feels that he is also a participant in the Spring Festival.

\section{Development Trends of Interactive Design in the Field of Environment Art Design}

\subsection{Development Trends of Interactive Design in the Field of Indoor Environment Art Design}

With the advent of the era of information media, people are more and more demanding of visual aesthetic feeling, and more and more vivid and vivid interior design forms are needed. With multimedia, users can understand all aspects of interior design information and ask for their own requirements, which is much more vivid and rich than physical objects, models or photographs of a static object. Developing a virtual reality interactive software platform based on broadband network is a trend of future interaction design in interior design. Different needs so that you can according to different users, combined with online search engines, navigation system, online store multimedia terminal, from the network game form, to create a strong understanding of space, movement and streamline proper perspective, and through the voice guidance enables the whole process to achieve the operation convenience, the use of visualization and interesting. The information processing system is used to collect, update, integrate and share information. In this virtual reality system, users 
can carry out all design activities on interior design. The database should include space database, furniture database, material database, budget database and other seed databases. Through the database, users can take the data arbitrarily according to their own requirements. Design system. The system should include learning function, association function, navigation function, and building model function. In this way, users can be reorganized and systematized after acquiring knowledge and information, and complete the design according to their own ideas and requirements. The media system can recommend or help users to design according to certain principles, provide a comparison of the advantages and disadvantages of the scheme, and the overall budget. The service exchange system includes the pre-design investigation and consultation system and the after-sale service system after the interior design is completed, which enables users and designers to have mutual consultation, communication and feedback of opinions and information.

\subsection{Development Trends of Interactive Design in the Field of Outdoor Environment Art Design}

Interactive design concept and its system based on this trend will also be more and more attention and promotion. It emphasizes multidisciplinary participation and considers factor modules, such as energy, land, water, materials and other natural resources. Outdoor environment design is particularly handy in the application of interactive design concept, and can get full prospects for development. With the development of electronic technology and digital technology, the interactive natural scenery design system will emerge as the times require. Using this design system, users can design mountain, water, trees, grass and clouds and other natural scenery and related architectural sketches in different outdoor environment layout, and arrange the scene according to the wishes of users, and make real-time panoramic preview. At the same time, based on keeping the authenticity of scenery, users can make various adjustments according to the needs, and use various test virtualization to enter the space to increase user experience and activeness and interest. In the concrete implementation of outdoor environmental art design, interactive experience devices and related services will also be added. The transmission feedback system may be a computer terminal, or may be an infrared sensing or other related technical device that can receive signals. After entering the scope of the space, the audiences can get relevant scenes or information hints, get information that individuals need to know, or feel that the environment changes the individual's entry. At the same time, the audience should make information feedback with the terminal. During the feedback period, the time spent by the audience needs to be controlled in a relatively short range, so that people are not tired. And the whole experience process is also designed to be relatively interesting. It's better to use voice, light, color and quality to mobilize people's vision, hearing, smell and taste, and get the effect of positive feedback. Finally, the feedback of these information can be processed in time and effectively, and the interaction and improvement of the information release will be targeted.

\section{Conclusion}

Interactive design can be widely used in the fields of architecture, landscape, indoor, public art works, product design and so on. It has a broad application prospect. In modern environmental art design, due to the acceleration of social progress, many design works only focus on function and aesthetics, often do not place themselves in the audience's consideration, while interactive design works solve this problem better. Today, the design should consider more and more users' physical and mental feelings, deeply analyze the characteristics of the works of environmental art design.

\section{Acknowledgment}

The paper is the result of Teaching Reform Project of Lanzhou Jiaotong University at the university level (Grant No. JGY201734) and the project funded by Natural Science Foundation of Gansu Province (Grant No. 1610RJZA045). 


\section{References}

[1] Liu Ning. Discussion of Development of Interaction Design in the Field of the Environmental Art Design [J]. Journal of Henan Institute of Engineering (Social Science Edition), 2011, 26(2): 88-90.

[2] Gui Yuhui, Hu Yujia. Research on the Core Concept, Educational Evolution and Practice of Interactive Design [J]. Design Research, 2017, 17(2): 93-99+128.

[3] Liu Hongxia, Ai Xiaoyan. Research on the interaction design for flipped classroom in informationization environment [J]. Computer Era, 2016(6): 98-100.

[4] Zhou Chengmin, Kaner Jake, Liang Shuang, et al. Furniture Showcase Innovative Design Based on Interactive Technology [J]. Packaging Engineering, 2015, 36(14): 18-22. 